\title{
A NEW SCAR MARKER OF HIGH SUGAR GENE IN SWEET SORGHUM [SORGHUM BICOLOR (L.) MOENCH]
}

\author{
Chen, Y. - PANG, H. B. - LI, X. M. - MA, L. J. - WANG, L. L. - Zhang, Y. - LI, Y. Y.* \\ College of Life Science, Shenyang Normal University \\ No. 253 Huanghe North Street, Shenyang, Liaoning 110034, China \\ *Corresponding author \\ e-mail: yueyinglicn@163.com
}

(Received 25 $5^{\text {th }}$ Apr 2019; accepted $16^{\text {th }}$ Jul 2019)

\begin{abstract}
This experiment used molecular marker technology to analyse high sugar genes, clone the target bands and the Random amplified polymorphic DNA (RAPD) molecular markers were converted into Sequence characterized amplified regions (SCAR) molecular markers, and additionally 120 RAPD primers were used to analyse female 3228B (sweet sorghum), paternal 3201B (ordinary sorghum) and their hybrids $\mathrm{F}_{5}$. The results showed that 95 of 120 pairs amplified products, 25 of them did not amplify products, so the amplification rate reached 79\%. The recombination rate of S512 and high sugar genes was 7\% in F5 populations. S512 amplified polymorphic bands were recovered, cloned and sequenced, its band length was $441 \mathrm{bp}$. According to the sequence, we transferred the RAPD to SCAR molecular markers and designed SCAR primer. We got the same amplification results with the RAPD in specific amplification progress of sweet sorghum F5 populations, thus the RAPD transfered to SCAR successfully, we called this $\mathrm{SCAR}_{\mathrm{S5} 12-441}$.
\end{abstract}

Keywords: Random amplified polymorphic DNA (RAPD), Sequence characterized amplified regions (SCAR), amplification, molecular marker, coseparation analysis

\section{Introduction}

Sweet sorghum (Sorghum bicolour (L.) Moench) is a variation of common sorghum (Vermerris, 2011), it has a strong resistance, high sugar content, high photosynthesis rates, high productivity, is one of the most important energy plants in the world (Wang et al., 2013; Lu et al., 2013). Sweet sorghum can applied in animal feed and brew as an energy plant, and produce syrup, making sugar. Research shows that the brix of sweet sorghum stems have high heritability, showing great effects on breeding variety (Zhang et al., 2011). We take Liao Tian 6 as a benchmark, the sugar brix of Liao Tian 6 is 18, the sugar brix higher than 18 are regarded as high sugar content. Studies show sugar brix traits of culms of sweet sorghum, is controlled by two major gnes add polygenes (Lu et al., 2012). And sugar contents characters were not a single gene, but have unbalanced multigenes besides a major gene (Wang et al., 2010). As biological research gradually entered the molecular level, molecular marker are more widely used, including germplasm resource research and breeding (Yang et al., 2016). Base on the application of DNA sequence polymorphism, Molecular Marker can mainly divided into three categories: (1) Includes restriction fragment length polymorphism marker and chromosome in situ hybridization marker with molecular hybridization at core. (2) Includes amplified fragment length polymorphism marker and sequence point marker with PCR reaction at core. (3) New molecular marking technique, includes single nucleotide polymorphism marker and expressed sequence tag. It has more advantages which sequence characterization amplified region marker based on RAPD of new molecular technology (Wu et al., 2016). It can overcome the shortcomings of high false 
negative and lacks of repetition that translate the specificity band generated by RAPD marker into SCAR marker (Luo et al., 2013; Wang et al., 2016).

At present, SCAR is used a lot in breeding. In resistance gene marker research, anoectochilus roxburghii polymorphic RAPD marker have been developed based on 20 anoectochilus roxburghii germplasm resource, and transforming specific band into SCAR marker, identify its specificity. Use SCAR marker gene to identify the resistance effect of Soybean anthracnose resistance gene (Gu et al., 2011). Transfer RAPD marker which closely-linked with aphid resistance gene to SCAR marker, and make SCAR determinations to $F_{3}$ and some resistant varieties ( $\mathrm{Li}$ et al., 2003), specific bands of $\mathrm{F}_{3}$ resistant individual obtained. This experiment aimed to make a RAPD molecular marker analysis to experimental populations, find a RAPD primer related to sweet sorghum's high sugar gene, and give target band cloning and sequencing, then translated into stable SCAR marker, reduce the complexity of field farming, establish the theoretical foundation for choosing fine sweet sorghum variety (Tan et al., 2013; Li et al., 2016).

\section{Materials and Methods}

\section{Plant material}

Sweet sorghum 3228B (as the female parent in this study) and common grain sorghum 3201B (as the male parent) were supplied by Liaoning Academy of Agricultural Sciences. We created $\mathrm{F}_{5}$ plants from the cross of $3228 \mathrm{~B} \times 3201 \mathrm{~B}$, and get total of 100 lines. We get the first leave under the fag leaf of the $\mathrm{F}_{5}$ plants as plant materials. These sorghums have the same genetic background, and the marker which identify the sugar content.

\section{Experiment methods}

DNA extraction of seedling stage

Methods apply modified cetyltrimethylammonium bromide (CTAB) (Li et al., 2009; Lan et al., 2015) to extract DNA of male parent, female parent and $F_{5}$ plants.

\section{DNA determination}

(1) Concentration measurement: absorbance of the diluted DNA were measured in different detecting waves which are $230 \mathrm{~nm}, 260 \mathrm{~nm}$ and $280 \mathrm{~nm}$.

(2) Electrophoresis detection: 0.7\% Agarose gel's preparation in ready: point sample, electrophoresis.

\section{Build near isogenic pool}

We use Bulked Segregation Analysis (BSA) (Yao et al., 2010) to analyze high sugar population and low sugar population. High sugar bulk: Take $1 \mu \mathrm{l}$ of DNA of 62 varieties of high sugar content sorghum. Low sugar bulk: Take $1 \mu$ of DNA of 38 varieties of low sugar content sorghum.

\section{Build RAPD-PCR reaction system and condition}

$25 \mu \mathrm{l}$ reaction system: which established by $25 \mathrm{mmol} / \mathrm{L} \mathrm{MgCl} 22.0 \mu \mathrm{l}, 10 \times$ Buffer $2.0 \mu \mathrm{l}, 10 \mathrm{mmol} / \mathrm{L} \mathrm{dNTPs} 1.5 \mu \mathrm{l}, 10 \mu \mathrm{mol} / \mu \mathrm{l}$ primer $1.0 \mu \mathrm{l}, 5 \mathrm{U} / \mu \mathrm{l}$ Taq enzyme $2.5 \mu \mathrm{l}$, 
DNA template (100 ng) $2 \mu \mathrm{l}$, and add ddwater to $25 \mu \mathrm{l}$. Reaction conditions: $94^{\circ} \mathrm{C}$ Initial denaturation $5 \mathrm{~min} \rightarrow\left(94^{\circ} \mathrm{C}\right.$ denature $20 \mathrm{~s} \rightarrow 50^{\circ} \mathrm{C}$ Primer annealing $30 \mathrm{~s} \rightarrow 72^{\circ} \mathrm{C}$ Primer extension $70 \mathrm{~s}) 35$ cycles $\rightarrow 72^{\circ} \mathrm{C}$ extension $10 \mathrm{~min} \rightarrow 4^{\circ} \mathrm{C}$ storage.

\section{Build SCAR-PCR reaction system}

Reaction system: which established by $10 \times$ Buffer $2.5 \mu, 10 \mathrm{mmol} / \mathrm{L}$ dNTPs $1.0 \mu \mathrm{l}$, $25 \mathrm{mmol} / \mathrm{L} \mathrm{MgCl} 22.5 \mu \mathrm{L}, 5 \mathrm{U} / \mu \mathrm{l}$ Taq enzyme $0.25 \mu \mathrm{L}, 10 \mu \mathrm{mol} / \mu \mathrm{L}$ S512F $0.5 \mu \mathrm{l}$, $10 \mu \mathrm{mol} / \mu \mathrm{L}$ S512R $0.5 \mu \mathrm{l}$, DNA template $1.0 \mu \mathrm{l}(100 \mathrm{ng})$, and add ddwater to $25 \mu \mathrm{l}$. Reaction conditions: $96^{\circ} \mathrm{C}$ Initial denaturation $5 \mathrm{~min} \rightarrow\left(94^{\circ} \mathrm{C}\right.$ denature $1 \mathrm{~min} \rightarrow 50^{\circ} \mathrm{C}$ Primer annealing $50 \mathrm{~s} \rightarrow 72^{\circ} \mathrm{C}$ Primer extension 1 min) 35 cycles $\rightarrow 72^{\circ} \mathrm{C}$ extension $10 \mathrm{~min} \rightarrow 4^{\circ} \mathrm{C}$ storage.

\section{Detection of PCR reaction products}

(1) $1.4 \%$ Agarose gel's preparation.

(2) Electrophoresis of PCR product.

\section{Recovery of target band}

We sterilize the needle and cut a few times at the polymorphism bands, then put the needle into RAPD-PCR reaction system, repeat this procedure several times and recovery the amplified different bands.

\section{Co-segregated Analysis}

Recombination rate $(r)=$ Commutative number/ (High sugar population number + Low sugar population number) $\times 100 \%$ (Wang, 2004).

Genetic distances $(\mathrm{cM})=[1 / 4 * \ln (1+2 \mathrm{r}) /(1-2 \mathrm{r})] * 100$.

\section{Marker map (Figure 1)}

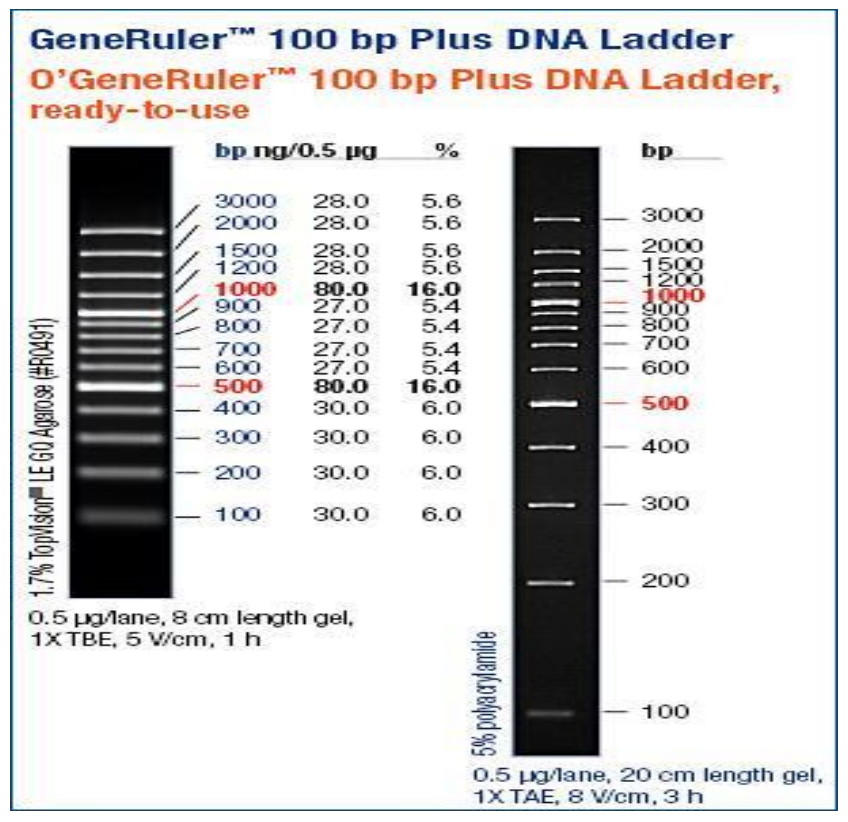

Figure 1. 100bp ladder marker 


\section{Results and Analysis}

\section{Purity analysis of DNA}

The electrophoretic pattern as shown in Fig. 2 is total DNA extracted by improved CTAB method. As seen in Fig. 2, these bands are clear and without degrade. Purity and concentration of the DNA which was measured with ultraviolet spectrophotometer show that $\mathrm{OD}_{260} / \mathrm{OD}_{230} \geq 2.0, \mathrm{OD}_{260} / \mathrm{OD}_{280} \geq 1.7-1.8$, further explain, extracted DNA under these conditions can be used in subsequent RAPD- PCR experiment analysis.

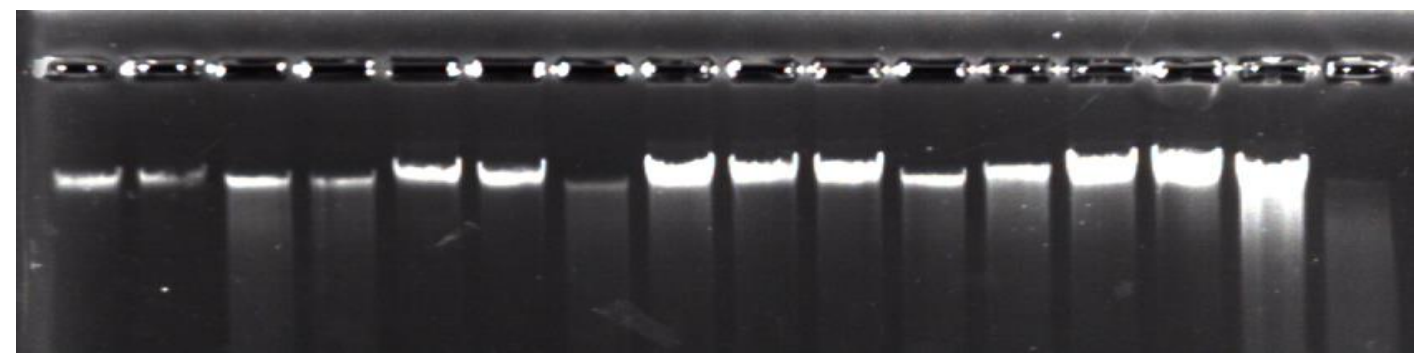

Figure 2. DNA electrophoresis gel results. Female parent (1) Male parent (2) High sugar individual (3-9) Low sugar individual (10-16)

\section{RAPD-PCR analysis of sweet sorghum high sugar gene}

In this study, with a random selected 120 RAPD primer, the RAPD molecular markers were used to analyze the Sweet sorghum (as the female parent in this study), common grain sorghum (as the male parent), high sugar gene bulk and low sugar gene bulk. The results show that the amplification rate is $79 \%, 95$ primers were amplified bands and 25 primers can not ampliy bands. Most of the primers can amplify more than 6 bands, primer S504 amplify the largest bands, but with low quality images. There was no obvious difference among high sugar gene bulk, low sugar gene bulk and the parents. Primer S506 ampliy 7 bands which are the clearest, and there are also with no obvious difference among high sugar gene bulk, low sugar gene bulk and the parents. Primers S507 have differences between parents and high sugar gene bulk or low sugar gene bulk. Primer S509 amplify the least bands and the bands haven't differences. The amplification results see in Fig. 3.

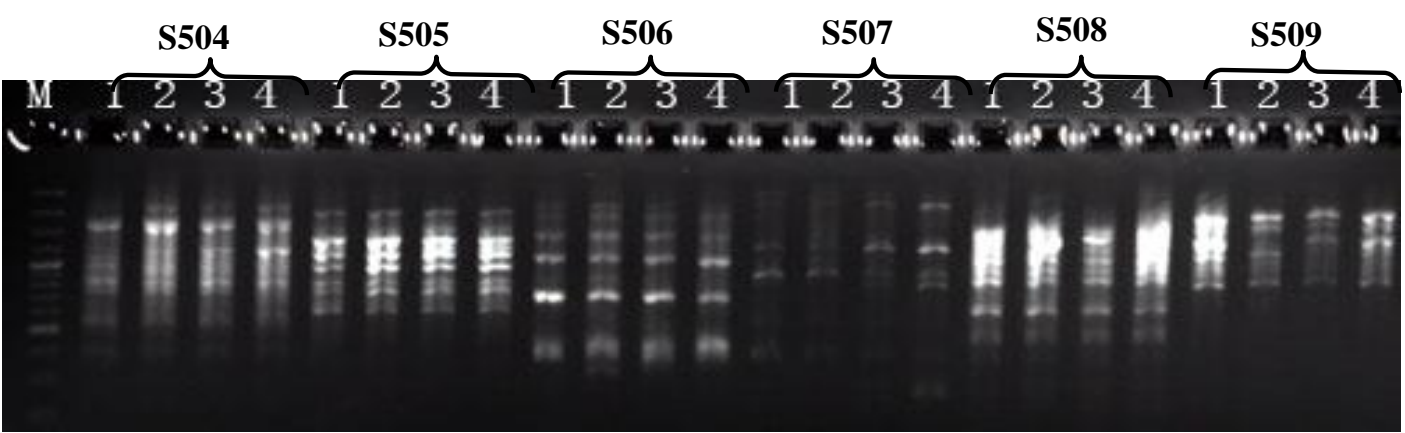

Figure 3. The PCR-RAPD amplification results of primer S504, S505, S506, S507, S508, S509. Female parent (1) Male parent (2) High sugar gene pool (3) Low sugar gene pool (4) Marker (M) 
Amplification result of primer S510-S513 showed that bands are amplified by 4 primers. The bands amplified by primer S510 showed high polymorphisms between female parent (1) and male parent (2) and have high definition, but there is no polymorphism between high sugar gene bulk (3) and low sugar gene bulk (4) Only one band amplified by primer S511 and unclear. The bands amplified by primer S513 are clear but there are no polymorphism different bands among parents, high sugar gene bulk and low sugar gene bulk. The bands amplified by primer S512 is clearest, and have different bands between the female parent (sweet sorghum) and high sugar gene bulk, but there are haven't different bands between the male parent (common grain sorghum) and low sugar gene bulk, this different bands located at 450bp (Fig. 4), Therefore, our study will continue PCR detection and cosegregation analysis of the primer S512 which is the clearest.

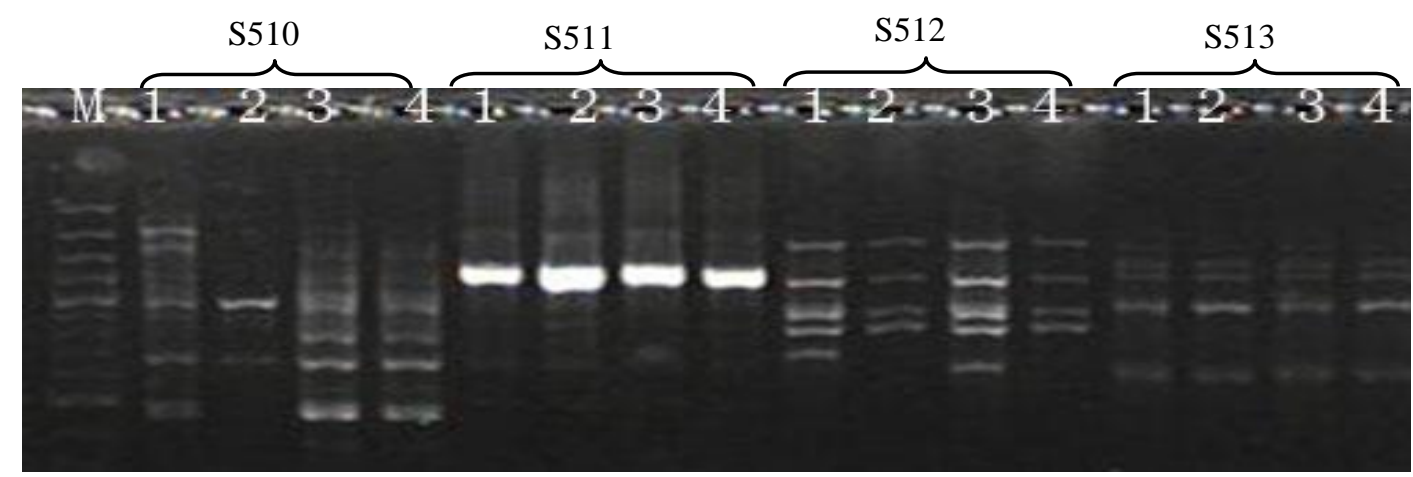

Figure 4. Amplification results of primer S510, S511, S512, S513. Female parent (1) Male parent (2) High sugar gene pool (3) Low sugar gene pool (4) Marker (M)

\section{RAPD polymorphism's cosegregation analysis of high sugar gene of sweet sorghum}

RAPD-PCR amplification results of the primer S512 in individual

By comparing the individual plant amplification results of parents, high sugar group and low sugar group, we reach that the bands amplified between female parent (sweet sorghum) and high sugar individual by primer S512 are more than the bands between male (common grain sorghum) and low sugar individual (Fig. 5).

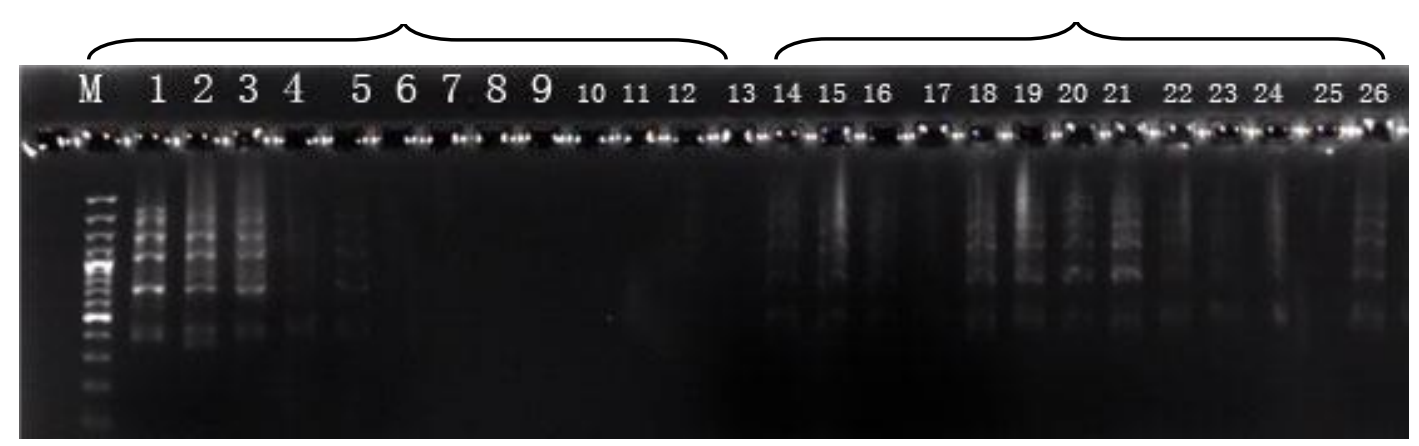

Figure 5. The single plant amplification results of primer S512. Low sugar individual (1-13), High sugar individual (14-26), Marker (M) 


\section{Recombination rates analysis}

To observe the amplification results of high sugar individual and low sugar individual by primer S512, we get 58 individuals were amplified polymorphism bands and 4 individuals not be amplified in high sugar bulk, and 3 individuals amplified polymorphism, 35 individuals not be amplified, the recombination rate is $7 \%$ (Table 1). Recover the amplified fragment in the end.

Table 1. Co-segregation of the S512-441 amplified polymorphic fragment in $F_{5}$

\begin{tabular}{c|c|c|c|c}
\hline \multirow{2}{*}{$\mathbf{F}_{5}$} & \multirow{2}{*}{ Total plants tested } & \multicolumn{2}{|c|}{ Polymorphic fragment } & \multirow{2}{*}{$\begin{array}{c}\text { Percentage of } \\
\text { recombination \% }\end{array}$} \\
\cline { 3 - 4 } & & Present & Absent & $7 \%$ \\
High sugar & 62 & 58 & 4 & \\
Low sugar & 38 & 3 & 35 & \\
\hline
\end{tabular}

\section{Recover and clone sequencing of polymmorphism marker}

\section{Recover target bands}

Recover the difference bands amplified by primer S512, the results of recovery showed that the bands is the same as the target band, both are 450bp (Figure 6).

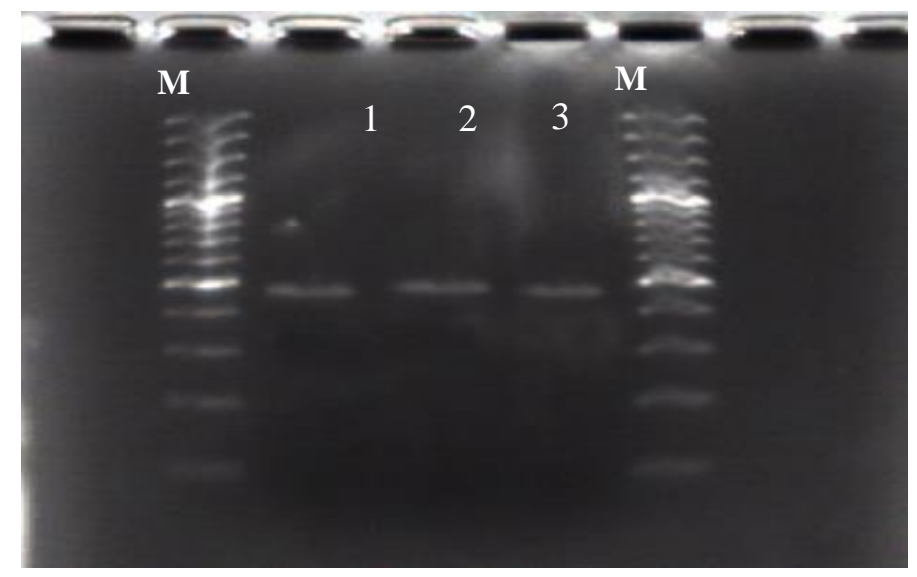

Figure 6. Recovered fragment of primer S512 (1-3)

\section{Cloning and sequencing}

Cloning and sequencing were given to the recovery difference bands, and results showed the fragment is $441 \mathrm{bp}$.

\section{Transform RAPD molecular marker to SCAR marker}

\section{RAPD primer design}

Basic sequence and primer design principles of specific primer S512, adding G+C base pairs and designed as follows specific primers sequence ends while avoiding hairpin.

S512F: 5'-ACAGGTGCGTACATCGAATG-3'

S512R: 5'-TTACAGGTGCGTTAATTGCC-3' 


\section{SCAR-PCR response analysis}

Above designed specific primer S512 were used to amplify the parents and two sets of individuals in SCAR-PCR. Results show that SCAR marker the same as RAPD marker of high sugar gene's chain reaction of sweet sorghum $\mathrm{F}_{5}$. Both female parent (sweet sorghum) and high sugar individuals are amplify a specific band at $450 \mathrm{bp}$ (Fig. 8), but male parent (common grain sorghum) and low sugar individuals haven't this specific band. It shows that SCAR marker is easy to distinguish and has strong specificity, so we can transform RAPD marker to stable SCAR marker successfully, named this marker SCAR $5512-441$ depending on the sequence results.

$\begin{array}{cccccc}1 & \text { GACTTAGGTT } & \text { TAAGTAAATA } & \text { TGGTCCATAT } & \text { GGTGTTGGGT } & \text { TATCCTATTT } \\ 51 & \text { CTTAATAGAA } & \text { ATTCAGCATA } & \text { GTGCAGAGTG } & \text { TCATTTCACT } & \text { ATATTTTGTT } \\ 101 & \text { ACAACAGGTG } & \text { CGTAGTATTC } & \text { AAGAGTAGCA } & \text { TTCAACTTAT } & \text { TCTACCCTAT } \\ 151 & \text { TTAAGTCAAA } & \text { TTAGACATGG } & \text { TGTCTAGGTT } & \text { GATTTTTGAG } & \text { CCAATAGTAT } \\ 201 & \text { AAACAACCAC } & \text { TCCATGGAAG } & \text { AGGGTGAACA } & \text { AATCACCACC } & \text { AGGCCCCTTC } \\ 251 & \text { TTAGAAAGCT } & \text { TTTCTCGATC } & \text { TTGGTATGCA } & \text { CATAAATGAA } & \text { GAACCAAACA } \\ 301 & \text { CAGAAGTCAC } & \text { AAACTGGGAA } & \text { GTCCTGAGAT } & \text { GAACTCAGAT } & \text { GGAGAAAGAA } \\ 351 & \text { GAGATACATG } & \text { AACTTCAACA } & \text { ACCTCGCATA } & \text { AGGAGAACAT } & \text { AGCTTATGGA } \\ 401 & \text { GAGCCCATGC } & \text { AGTTGATCTT } & \text { TGCCTTGTCT } & \text { TTATGAGCAG } & \text { GACACACTTT } \\ 451 & \text { ATCCAGCAGC } & \text { TAGGGATAGC } & \text { AGGAGAGGCC } & \text { ATGCTGACTG } & \text { GTGGATGCCA } \\ 501 & \text { GATCCGCTGC } & \text { TCCGCAGTTG } & \text { GGCTCGCTGG } & \text { ATCCAGCCTG } & \text { TCCACGCAGT } \\ 551 & \text { CCGGTAGGAG } & \text { CACGGATCCA } & \text { CTGCTCTCCA } & \text { GATCTACTGC } & \text { GACTAGTGCG } \\ 601 & \text { TGGGCTGGGG } & \text { CTCACCAGAT } & \text { CTGCTGCTGC } & \text { CAGTTGTCTA } & \text { CTTGTGATGG } \\ 651 & \text { GAAGC } & & & & \end{array}$

Figure 7. The recovered fragment sequencing results of S512

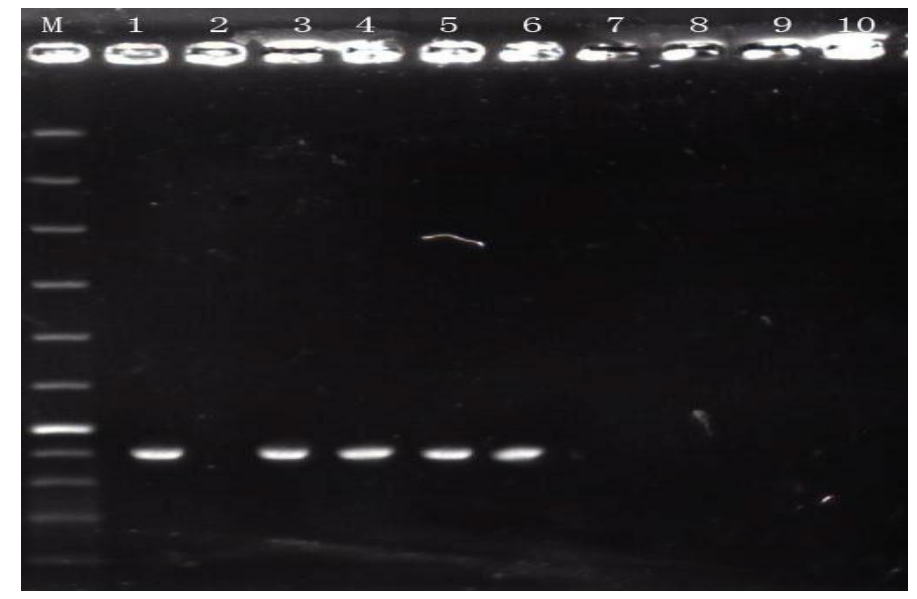

Figure 8. Part of individuals test results of primer S512's SCAR marker. Female parent (1) Male parent (2) High sugar individual (3-6) Low sugar individual (7-11) Marker (M)

\section{Conclusion}

In this experiment, 120 RAPD primers selected at random, the RAPD techniques were used for molecular marker of experimental population to find the RAPD primer related to high sugar gene of sweet sorghum. In recent years, there are great achievements in fruit varieties identification, hybrid identification and mutant detection, construction of molecular genetic maps, gene map, gene diversity and pedigree analysis 
through RAPD technology (Li et al., 2018). Because of RAPD marker's poor stability and repeatability, it's difficult to use in crop genetic breeding and assistant selection. We clone and sequence target band, to get good stability and high reproduction SCAR marker. The primer used by SCAR marker is longer than RAPD marker and the primer sequence completely complement with template DNA. To get good stability and high reproduction results, we should better amplify in rigorous conditions (Xiong et al., 2010).

Random selecting 120 RAPD primers, analyzing sweet sorghum (female parent), common grain sorghum (male parent), high sugar gene bulk and low sugar gene bulk by the RAPD marker. The result showed that 95 primers could produce bands, 25 primers could not produce bands, amplification rate is $79 \%$. Because of the bands amplified by primer S512 is the clearest, we observe the results of high sugar individual and low sugar individual amplified by primer S512. In high sugar population, 58 plants amplified polymorphic bands, 4 plants haven't amplified, but in low sugar population, 3 plants amplified polymorphic bands, 35 plants haven't amplified, amplification rate is $7 \%$, genetic distances is $7.5 \mathrm{CM}$. Recovering polymorphic bands of PCR production amplified by specific primer S512 and cloning and sequencing. SCAR specific primers were designed.

S512F: 5'-ACAGGTGCGTACATCGAATG-3'.

S512R: 5'-TTACAGGTGCGTTAATTGCC-3'.

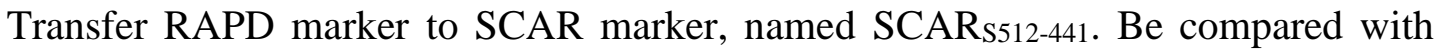

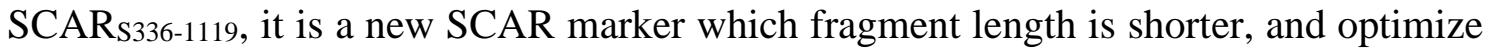
the SCAR marker's reaction system.

\section{Discussion}

We can see that it is low efficiency that transfer RAPD marker to SCAR marker. The cause may be: (1) When designing primers, often contain corresponding 10 base RAPD primer. Because of the original polymorphism can be detected. Even as the increases of amplification's stability and success rate, the transformation of RAPD primers was still affected. (2) Transform specific fragment of RAPD to SCAR attention must be paid to primer design length and PCR reaction condition (for instance, when the anneal temperature is constant, the anneal time and extend time should not be too long). (3) Take many factors into consideration, for instance, base sequencing of sequence's head and tail is instability, annealing temperature of specific transform RAPD to SCAR marker primer, the design of primer in SCAR transformation is closer to the medium of sequence, instead of start at both ends of sequence. However, in practical operations, because of these factors, in alone or in combination, the transformation efficiency of transform RAPD marker to SCAR is reduced. These errors should be minimized (Kula, 2012; Li et al., 2014; Liu et al., 2016).

Using identified high sugar population and low sugar population to test SCAR marker closely linked sweet sorghum's high sugar gene. It has great significance to apply it in practice, and use this marker in high sugar gene variety test.

This experiment optimized optimal reaction system and reaction conditions of RAPD molecular markers and optimal reaction system of SCAR marker, recovery polymorphic bands of PCR product amplified by specific primer S512, and cloning and sequencing. Polymorphic bands linked to sorghum $\mathrm{F}_{5}$ high sugar gene length of $441 \mathrm{bp}$. The RAPD 


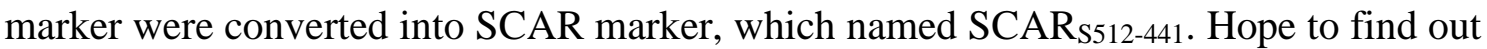
more SCAR marker to identify sorghum with high sugar content in the future.

Acknowledgements. The research was partly supported by key project of Liaoning Province Department of Education (2019) and Major incubating project of Shenyang Normal University.

\section{REFERENCES}

[1] Gu, Y., Han, Q. H., Wang, W. T., Li, S. W., Sun, D. L., Wu, F. (2011): Application of common bean anthracnose resistance gene SCAR markers in snap bean disease resistance identification. - Acta Horticulturae Sinica 38(5): 911-920.

[2] Lan, B. X., Wang, L., Wu, Z. K. (2015): Rapid miniprep extraction of genomic DNA from micro-endosperm maize with modified CTAB method. - Genomics and Applied Biology 34(1): 190-194.

[3] Li, Y. Y., Zhao, S. H., Yang, L. G. (2003): Study on the molecular markers linked to aphid resistance gene of sorghum. - Acta Agronomica Sinica 29(4): 534-540.

[4] Li, N. Z., Tao, S. Y., Li, Y. Y. (2008): RAPD primers screening and polymorphism analysis of genome on sorghum. - Biotechnology 18(4): 7-10.

[5] Li, R. H., Xia, Y. S., Liu, S. Z. (2009): CTAB - improved method of DNA extraction in plant. - Research and Explorationn in Laboratory.

[6] Li, Q., Liu, Z. Z., Zeng, Z. (2014): Two new RAPD - SCAR markers among wild populations of trachidermus fasciatus. - Freshwater Fisheries 44(3): 17-23.

[7] Liu, S. L., Wang, X. H., Jiang, C. X., Yuan, W., Zhang, J. H. (2016): RAPD-PCR analysis on different germplasm resources of Curcumae Rhizoma. - China Medicine 47(17): 3098-3102.

[8] Li, Y. Y., Li, C. Y., Xing, H. Q. (2016): Research on establishment of head smut of sorghum by using SCAR marker. - Journal of Shenyang Normal University Social Science Edmon (Natural Science Edition) 34(4): 468-472.

[9] Lu, F., Zou, J. Q., Duan, Y. H. (2012): Genetic analysis of stalk sugar content related traits in sweet sorghum (Sorghum bicolor). - Journal Of China Agricultural University 17(06): 111-116.

[10] Lu, F., Zou, J. Q., Duan, Y. H. (2013): Correlation study of stalk sugar content and main agronomic traits. - Liaoning Agricultural Sciences 6: 1-4.

[11] Luo, F. X., Mao, P., Yao, Y. S. (2013): SCAR molecular marker technology and its application in aquatic animal research. - Journal of Jilin Agricultural Sciences 4: 251252.

[12] Tan, Y., Li, Z. H., Li, J. L. (2013): Application of RAPD Molecular Marker Technology in Plant Research. - Journal of Anhul Agricultural Sciences 41(25): 10236-10238.

[13] Vermerris, W. (2011): Survey of genomics approaches to improve bioenergy traits in maize, sorghum and sugarcanefree access. - Journal of integrative plant biology 53(2): 105-119.

[14] Wang, L. M., Huang, R. D., Jiao, S. J. (2010): Gene effect analysis of sugar content of sweet sorghum. - Crops 4: 62-64.

[15] Wang, H. F., Xin, N., Wu, X. H., Pei, Z. Y. (2013): Current status, problems and countermeasures of sweet sorghum breeding. - Crops 2: 23-26.

[16] Wang, J. K., Li, M. J., Wang, J. M., Wei, K. H., Gu, L., Lin, W. M., Zhang, J. Y., Zhang, Z. Y. (2016): Development of RAPD-SCAR marker for Anoectochilus roxburghii and their utilization to assess genetic diversity of germplasm. - China Medicine 47(1): 122129.

[17] Wu, Y., Zhou, K. H., Fang, R. (2016): Review of the core collection for horticultural plants based on molecular markers. - Journal of China Capsicum 3: 31-39. 
[18] Xiong, F., Zheng, M. J., Xie, B. G. (2010): Development of SCAR markers based on RAPD and SRAP for rapid identification of pleurotus sajor - caju strain. - Acta Agricultural Turae Universitatis Jiangxiensis 32(3): 601-607.

[19] Yang, H. X., Wu, X. H., Nong, Q. L. (2016): Research progress of sugarcane brown rust resistance gene and its molecule markers. - Sugar Crops of China 38(6): 57-61.

[20] Yao, G. X., Li, J. J., Zhang, Q., Hu, G. L., Chen, C., Tang, B., Zhang, H. L., Li, Z. C. (2010): Mapping QTLs for grain weight and shape using four sister near isogenic lines in rice (Oryza sativa L.). - Acta Agronomica Sinica 36(8): 1310-1317.

[21] Zhang, X. Y., Zhao, W. J. (2011): Study advance in brix in sweet sorghum. - Shanxi Agricultural Science 39(6): 616-618.

[22] Zou, J. Q., Zhu, K., Wang, Y. Q., Li, Y. Y. (2010): Study on inheritance and molecular makers of sorghum resistance to head smut physiological race 3. - Scientia Agricultura Sinica 43(4): 713-720. 